\title{
Characterization and Analysis of Extraction Process-parameter of Pandanus tectorius (Screw-pine) Natural Fiber for Polymer Composites
}

\author{
Afolabi Lukmon Owolabi* and Puteri Sri Melor Megat-Yusoff \\ Mechanical Engineering Department, University Technology Petronas, 32610 Seri Iskandar, Malaysia
}

\begin{abstract}
Natural cellulose fiber extract from Pandanus tectorius (Screw pine) leaves is comprehensively investigated as viable alternative for synthetic based fibers made from petro-chemical which is non-degradable and toxic. Pandanus tectorius leaves fiber is extracted and investigated as reinforcement in polymer composite for engineering applications. The habitant are easily found and grown along mangroves and in local jungles located at shallow water. The plant can grow up to 14 meters tall. In order to use these continuous cellulose fibers as reinforcement in polymer composites, the microstructural analysis and yield content analysis were carried out using SEM micrographs to establish the certainty of using them as reinforcement fiber. The alkaline, bleaching and combined alkaline-bleach treatment is utilized in extraction of the cellulose fiber to evaluate the effect on the mechanical property. The cellulose percentage of the fiber was increased as the concentration and soaking time were increased. The extraction process resulted in $73 \%$ cellulose percentage for $10 \mathrm{wt} \% \mathrm{NaOH}$ and 120 minutes treatment. Hence, it caused $87 \%$ increment in cellulose percentage compared to the untreated leaf.
\end{abstract}

Keywords: Pandanus tectorius; Fibers; Chemical properties; Mechanical properties; Thermal properties; SEM

\section{Introduction}

Artificial mineral based fibers composites such as glass, aramid, ceramic and carbon fibers made from hydrocarbon resources are widely used in industries for different applications in textile, automobile, paint and plastic industries [1,2], due to their applicability and adaptability. However, limitation effect on their by-product, skin irritation, harmful chemical constituents, costly operation and nonbiodegradable nature contributes to environmental degradation [3]. Natural fiber composites are potential alternatives to mitigate the problems associated with conventional composite. These composites are gaining importance due to their non-carcinogenic, bio-degradable nature and are very cost effective material especially in building and construction purpose, packaging, automobile and railway coach interiors and storage devices [4]. Possessing characteristics of low weight, higher strength, higher stiffness, environmental friendly, low cost of manufacturing and abundance in supply $[2,5,6]$, natural fiber composites have gained interest and attention from researchers and practitioners in the composite industries. These can be potential candidates for replacement of high cost glass fibre for low load bearing applications. Thus far, considerable amount of energy is been channelled by several researchers towards using this fiber composites in various applications, more so due to their competitive properties, replicability and huge availability.

Natural cellulose fibers have been frequently used as the reinforcement component in polymers to add the specific properties in the final product [7-11]. The study of Kim et al. [12] investigated the influence of fiber extraction and surface modification on the mechanical properties using bamboo green composite. Vinyl-ester binder was used in a vacuum moulding techniques comprising of alkali, steam and chemical extraction. The results shows tensile properties of bamboo fiber bundle decreased in all conditions compared to raw bamboo fiber, but interfacial shear strength increased with chemical treatment due to the effective removal of hemicellulose and lignin from surface of bamboo fiber. Kommula et al. [13] extracted fiber strands from Napier grass and investigated the effect of acetic acid treatment thermophysical and chemical properties. The acid treatment was carried out using glacial acetic acid solution at three different concentrations $(5,10$, and 15\%) for $2 \mathrm{~h}$. Chemical analysis indicated lowering of amorphous hemicellulose content on acid treatment. Arundo donax L. leave fiber reinforced polymer composite was studied by Fiore et al. [8] for their microstructure, chemical composition and mechanical properties.

There has been relatively little research carried out on fibers of the screw pine plant leaves for possible utilization as fillers in polymer reinforcement composite and its introduction in industrial uses is recent compared to other lignocellulosic fibers such as jute, flax and sisal. For this reason, the screw pine plant is not profitably planted for mass production and most of the plant materials are consume in local production of mat, beddings, chairs, basket etc. In the present study, extraction process of the Pandanus tectorius leaves were conducted in two phase; alkali treatment only and combination of alkali and bleaching. The influence of chemical concentration used and soaking time on cellulose percentage and tensile strength of the extracted fiber were studied. The relationship between cellulose percentage and tensile strength is also explored. Morphology of the extracted fiber was also investigated. Using the extracted fiber under optimized conditions, corresponding composites were fabricated and tested.

\section{Materials and Methods}

\section{Materials}

The main material used in the study was Pandanus tectorius (Screw pine) leaves as the main source of cellulose fiber. The fiber was

*Corresponding author: Lukmon Owolabi Afolabi, Department of Mechanical Engineering, University Technology Petronas, 32610 Seri Iskandar, Malaysia, Tel: 00601026-552-63; E-mail: afoolabs@gmail.com

Received November 12, 2017; Accepted January 28, 2018; Published February 08, 2018

Citation: Owolabi AL, Megat-Yusoff PSM (2018) Characterization and Analysis of Extraction Process-parameter of Pandanus tectorius (Screw-pine) Natural Fiber for Polymer Composites. J Material Sci Eng 7: 425. doi: 10.4172/2169-0022.1000425

Copyright: (c 2018 Owolabi AL, et al. This is an open-access article distributed under the terms of the Creative Commons Attribution License, which permits unrestricted use, distribution, and reproduction in any medium, provided the original author and source are credited. 
extracted with chemical means using alkali treatment and followed with bleaching to obtain high quality cellulose percentage. The Screw pine leaves were obtained from local shop at Kuala Kangsar, Perak. The leaves were in the form of a processed mat; cut, picked to remove torn, soaked in fresh stagnant water for several weeks and mild heating of the leaves surface. All the processes were assumed to have no appreciable effect on the structural and chemical composition of the fiber.

\section{Chemical reagents}

All chemicals and reagents utilized are of standard quality and were purchased from a reputable supplier. The alkali treatment involved sodium hydroxide $(\mathrm{NaOH})$ diluted to the desired concentrations which were $2-10$ wt. $\%$ with increment of 2 wt.\% concentration. In bleaching process, sodium chlorite $\left(\mathrm{NaClO}_{2}\right)$ was used and was dissolved from powder to solution of 1,2 and 3 wt.\% concentration. In determining the cellulose content of the extracted fiber, several chemicals were used such as potassium dichromate $\left(\mathrm{K}_{2} \mathrm{Cr}_{2} \mathrm{O}_{7}\right)$, ferrous (II) ammonium sulphate $\left(\mathrm{Fe}(\mathrm{NH} 4) 2(\mathrm{SO} 4)_{2} \cdot 6 \mathrm{H}_{2} \mathrm{O}\right)$, sulphuric acid $\left(\mathrm{H}_{2} \mathrm{SO}_{4}\right)$, and sodium hydroxide $(\mathrm{NaOH})$. Each chemical was prepared according to Technological Association of the Pulp and Paper Industry (TAPPI) Standard T203. The epoxy used in the fabrication of the cellulose based polymeric composite was EpoxAmite 100 Laminating System with hardener, 102 Medium Hardener.

\section{Extraction of cellulose}

Pandanus tectorius (Screw pine) mat was washed thoroughly with distilled water and dried under the sun. It was cut into $12 \mathrm{~cm}$ long and 3 $\mathrm{cm}$ wide strips and weighed accordingly. Each strip was approximately 0.3-0.35 grams. The leaves were treated with $2 \%$ up to $10 \%$ of $\mathrm{NaOH}$ at $200^{\circ} \mathrm{C}$ for 60 and 120 minutes. The ratio of the leaves to liquor was $5: 300(\mathrm{~g} / \mathrm{ml})$. The leaves were washed with distilled water after each treatment and were dried under the sun for 3 days.

Alkali treatment: Figure 1 displayed the visual inspection of the Pandanus tectorius (Screw pine) before and after under-going alkali treatment and varying percentage concentration and soaking period.

Following the pre-treatment process, the screw-pine strips were subjected to alkali treatment at 2 wt. $\%$ concentration of $\mathrm{NaOH}$ for 60 minutes soaking times and temperature of $170^{\circ}$ inside the oven. The ratio of leaves to liquor was $5: 300(\mathrm{~g} / \mathrm{ml})$. The treatment was repeated with 120 minutes soaking time. The concentration of $\mathrm{NaOH}$ was then increased systematically to 4, 6, 8 and $10 \mathrm{wt}$.\% for both soaking times of 60 and 120 minutes. All of the alkali treated screw-pine strips were

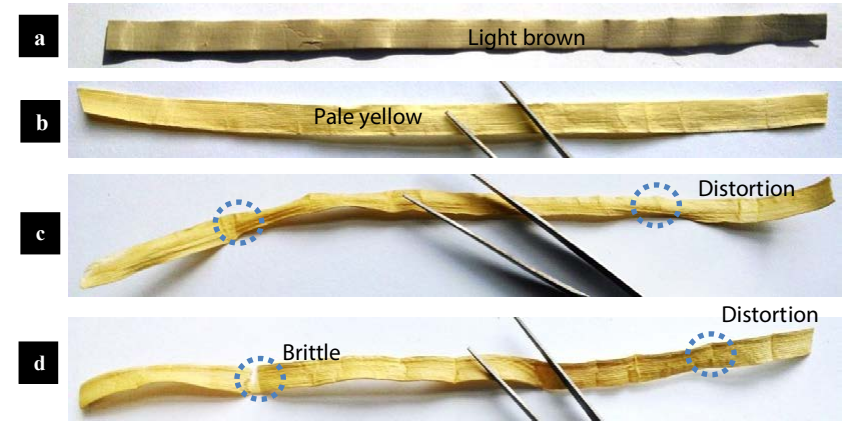

Figure 1: Screw-pine strip before and after alkali treatment and varying percentage concentration of $\mathrm{NaOH}$ and soaking time: (a) Untreated Screwpine strip, (b) $2 \mathrm{wt} . \% \mathrm{NaOH}$ with 120 minutes Soaking Time, (c) $8 \mathrm{wt} . \% \mathrm{NaOH}$ with 120 minutes Soaking Time and (d) 10 wt.\% NaOH with 60 minutes Soaking Time. washed thoroughly using distilled water to neutralize the remaining alkali and dried completely for 3 days under the sun. The selection of concentration and soaking time for $\mathrm{NaOH}$ were based on previous studies, findings and optimum performance.

Bleaching treatment: Figure 2 displayed the visual inspection of the Pandanus tectorius (Screw pine) after under-going combined alkali and bleaching treatment at varing percentage concentration and soaking period. Fibers extracted at 2, 4 and $6 \mathrm{wt} . \% \mathrm{NaOH}$ concentration during the alkali treatment were further subjected to bleaching process using $\mathrm{NaClO}_{2}$ solution. The bleaching process started with $1 \mathrm{wt} . \%$ concentration of the $\mathrm{NaClO}_{2}$ solution. The mixture of 29 screw pine strips in $\mathrm{NaClO}_{2}$ was placed inside the oven at $170^{\circ} \mathrm{C}$ for 60 minute soaking time. The ratio between screw pine strips and liquor was $5: 300(\mathrm{~g} / \mathrm{ml})$. The process was repeated at 2 and $3 \mathrm{wt} . \%$ concentration of $\mathrm{NaClO}_{2}$ at both soaking times of 60 and 120 minutes. All of the bleached screw pine strips were neutralized by washing thoroughly using distilled water. The leaves were dried under the sun for 3 days. The selection of concentration and soaking time for $\mathrm{NaClO}_{2}$ were based on previous related work and findings.

\section{Fabrication methods}

The Vacuum Resin Infusion (VRI) Process was employed in the fabrication of the continuous cellulose fiber (CCF) in this study. The corresponding CCF was placed on one-sided coated mould with wax in order to avoid fiber stacking on the mould during demoulding process. The CCF were vertically aligned and arranged into three layers with different arrangement to avoid gaps between fibers and to reduce porosity. A highly permeable medium of peeling ply and distribution mesh were laid over the surface of the fiber. The whole assembly was enclosed in a vacuum bagging film and sealed with sealant tape. The epoxy resin was 32 injected into the assembly with ratio of epoxy to hardener of 10:3 (w/w) under vacuum pressure. The composite was cured at $70^{\circ} \mathrm{C}$ for 4 hours inside the oven and naturally cooled down to room temperature. The composite was then demoulded.

\section{Characterization and measurements}

There are different types of characterization methods used in determining the quality of the extracted fibers. However, the present study utilizes the cellulose content determination, microstructural analysis and tensile strength test.

Continuous cellulose determination: Each screw pine strip undergoing alkali and combined alkali-bleach treatment was analysed for its cellulose content based on Technical Association of the Pulp and Paper Industry (TAPPI) standard; T203. The extracted solutions were used in the amount of $25 \mathrm{ml}$. The extracted solution was then added with $10.0 \mathrm{ml}$ of $0.5 \mathrm{~N}$ potassium dichromate solutions. $50 \mathrm{ml}$ of concentrated

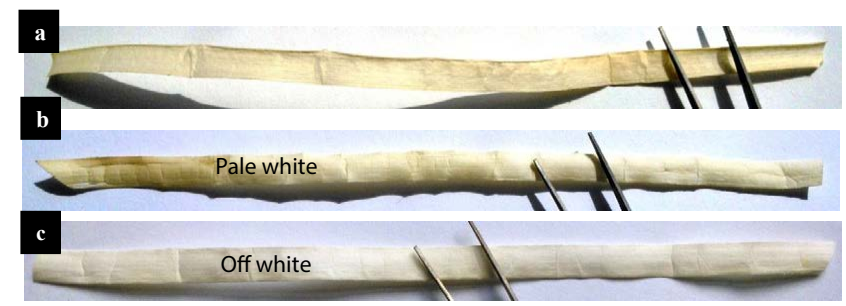

Figure 2: Visual Inspection on Screw-pine Strips after bleaching treatment at varying percentage concentration of $\mathrm{NaClO}_{2}$ and soaking time: (a) 1 wt. \% $\mathrm{NaClO}, 60$ minutes soaking time, (b) $2 \mathrm{wt} \% \mathrm{NaClO}_{2}, 60$ minutes soaking time, (c) 3 wt. $\% \mathrm{NaClO}_{2}, 120$ minutes soaking time. 
$\mathrm{H}_{2} \mathrm{SO}_{4}$ was added cautiously followed by $50 \mathrm{ml}$ of water after 15 minutes and cooled to room temperature. 2 to 4 drops of Ferron indicator were added and titrated with $0.1 \mathrm{~N}$ ferrous ammonium sulphate solutions to a purple colour. The amount of ferrous ammonium sulphate solution used was recorded to calculate the cellulose percentage by using eqn. (1) and repeated five times to obtain an average measurement.

$$
\text { Cellulose } \%=100-\frac{\left(6.58\left(V_{2}-V_{1}\right) \times N \times 20\right)}{(A \times W)}
$$

Where; $\mathrm{V}_{1}$ - titration of the pulp filtrate, $30 \mathrm{ml} ; \mathrm{V}_{2}$ - Blank titration, $\mathrm{ml} ; \mathrm{N}$ - Exact normality of the ferrous ammonium sulphate solution; A - Volume of the pulp filtrate, $\mathrm{ml}$; W - Weight of dried pulp specimen, $\mathrm{g}$.

Morphological analysis: Screw-pine strips were subjected to microstructural analysis using Field Emission Scanning Electron Microscope (FESEM) and Scanning Electron Microscope (SEM). The morphological structure of the un-treated screw-pine leaf was also analysed as a control. The morphology was observed using SUPRA55VP with an accelerating voltage of $3 \mathrm{kV}$. The images were digitally recorded and analysed for changes in the morphology due to the varying extraction process parameters. The microstructure analysis provided relevant information on the fiber-matrix interface and the fracture characteristics of the composite.

Mechanical properties analysis: Two types of tensile strength test were conducted to investigate the effects of varying extraction parameters in the present study. However, only the tensile strength of the single cellulose fiber after being treated with alkali and combined alkali-bleach will be presented as well as untreated single fiber as the control sample. Aside from the single cellulose fiber, tensile strength of the cellulose fiber composites was also measured. The results were compared with other cellulose-based composites. The entire tensile strength test was repeated five times and an average value reported.

Cellulose fiber composite: Tensile strength of single fiber was based on ASTM 3822 using Titus Olsen Universal Tensile Machine with 100 $\mathrm{N}$ load cells. The machine was equipped with pneumatic system in clamping, with adhesive layer for better gripers. The crosshead speed was $1.0 \mathrm{~mm} / \mathrm{min}$ with $50 \mathrm{~mm}$ gauge length. Tests were conducted at $55 \%$ relative humidity and at $23^{\circ} \mathrm{C}$. All data were recorded digitally.

Continuous cellulose fiber composite: Tensile strength of extracted cellulose fiber composite was determined using ASTM 3039. The specimen's dimensions were $230 \mathrm{~mm} \times 16 \mathrm{~mm} \times 1.6 \mathrm{~mm}$. Extensometer gauge length was $50 \mathrm{~mm}$ with $2 \mathrm{~mm} / \mathrm{min}$ constant crosshead speed. Test was conducted using Zwick/Roell Z005 universal testing machine with $5 \mathrm{k} \mathrm{N}$ cell load. The composite was clamped through a set of mechanical springs and mechanical zigzag gripers. All tests were conducted at $55 \%$ relative humidity and approximately $23^{\circ} \mathrm{C}$ temperature. Data obtained were recorded digitally.

\section{Results and Discussion}

\section{Extraction of cellulose}

The chemical composition of each of the fibers after under-going alkali and bleaching treatments methods are determined by examining their cellulose content. An un-treated screw-pine fiber, alkali treated fiber and bleach treated samples were all analysed and compared. The un-treated screw-pine fiber is used as control sample. The fiber content is very important due to the effect it has on mechanical properties, particularly, tensile strength where engineering application is required.

Alkali treatment: Naturally, the cellulose content of an un-treated screw-pine is estimated at $37 \%[14,15]$, However, the present study utilized screw-pine mat made from the leave which is expected to have slightly higher cellulose content due to pre-treatments undergone. Table 1 shows the effect of alkali concentration on the average extracted cellulose percentage upon varying concentration of $\mathrm{NaOH}$ and soaking time. The fiber cellulose content increases with the increase in volume concentration and soaking time for all the samples. A $75 \%$ cellulose content was extracted for $10 \mathrm{wt} . \% \mathrm{NaOH}$ treated for 120 minutes soaking time, thus when compared with untreated screwpine leaf a $45 \%$ cellulose percentage enhancement is achieved. The total average cellulose fiber extracted in all sample is $42 \%$, indicating a high content of lignin, pectin and hemicellulos was successfully removed thereby producing an effective treatment for extraction of cellulose fiber. Similar claims of effective alkaline treatment in breaking down the bond in material have been reported elsewhere $[13,16]$.

The results indicates that increase in alkali concentration increases the amount of cellulose fiber in extraction process but the correlation effect of soaking time was not reported. Many other researchers have studied the effect of soaking time in the extraction process of cellulose content from various plants and found that the soaking time is at variance depending of other parameters such as type of treatment solution, concentration, extracting temperature, materials type etc. [17-19]. The summary of the enhancement of the cellulose extraction with increase in the alkali content and soaking time is shown in Table 1.

Increasing the concentration from $2 \mathrm{wt} . \%$ to $10 \mathrm{wt} . \%$ resulted in $34 \%$ increment in cellulose percentage during the 60 minutes treatment. However, less than $12 \%$ enhancement in the extraction of the cellulose fiber is observed in soaking time of 60 minutes to 120 minutes in 4 wt.\% to $6 \mathrm{wt}$ \% samples. A linear regression analysis performed showed similar trend in the 60-120 minutes soaking time. This increment was smaller at $36 \%$ for the same concentration range during the 120 minutes treatment. 120 minutes soaking time gave higher amount of extracted cellulose percentage compared to that at 60 minutes soaking time. For instance, extraction at $2 \mathrm{wt} . \% \mathrm{NaOH}$ for 120 minute soaking time results in $18 \%$ higher cellulose percentage than extraction at 2 wt.\% $\mathrm{NaOH}$ for 60 minutes. However, the influence of soaking time is lesser at higher alkali concentration. For example, at $8 \%$ concentration of $\mathrm{NaOH}$, extracting the fiber for 120 minutes only resulted in $7 \%$ more cellulose percentage compared to that at 60 minutes. The similar result of significant influence for alkali concentration in treatment had reported elsewhere [20,21].

Combined alkali and bleaching treatment: Further treatment was carried out with bleaching of some selected samples. The extracted fibers from alkali treatment at 2, 4, 6 and 8 wt.\% concentration of $\mathrm{NaOH}$ at both 60 and 120 minutes soaking times were selected. Table 2 shows the measured values and average values obtained after the combined alkali-bleach treatment extracted cellulose percentage upon varying concentration of $\mathrm{NaOH}$ and soaking time. The discussion here is based on four different parts (a, b, c and d in Table 2).

\begin{tabular}{|c|c|c|c|c|c|c|c|}
\hline \multirow{2}{*}{\multicolumn{2}{|c|}{$\begin{array}{l}\text { Alkali treated Pandanus tectorius } \\
\text { Screw-pine leaf extraction process }\end{array}$}} & \multicolumn{6}{|c|}{ Wt.\% Conc. of $\mathrm{NaOH}$} \\
\hline & & 0 & 2 & 4 & 6 & 8 & 10 \\
\hline \multirow{4}{*}{$\begin{array}{l}\text { Soaking Time } \\
\text { (mins) }\end{array}$} & 30 & 33 & 39 & 42 & 46 & 52 & 57 \\
\hline & 60 & 39 & 45 & 53 & 57 & 65 & 69 \\
\hline & 90 & 41 & 50 & 58 & 65 & 69 & 75 \\
\hline & 120 & 42 & 54 & 63 & 68 & 72 & 79 \\
\hline \multicolumn{2}{|c|}{ Average cellulose content (\%) } & 38 & 46 & 53 & 58 & 63 & 70 \\
\hline
\end{tabular}

Table 1: Correlation of e soaking time, percentage by weight concentration in extraction process of fiber cellulose content. 
Citation: Owolabi AL, Megat-Yusoff PSM (2018) Characterization and Analysis of Extraction Process-parameter of Pandanus tectorius (Screw-pine) Natural Fiber for Polymer Composites. J Material Sci Eng 7: 425. doi: 10.4172/2169-0022.1000425

Page 4 of 8

\begin{tabular}{|c|c|c|c|c|c|c|}
\hline \multirow{2}{*}{\multicolumn{2}{|c|}{$\begin{array}{l}\text { Combined Alkali and Bleaching treated Pandanus tectorius Screw-pine } \\
\text { leaf extraction process }\end{array}$}} & \multirow{3}{*}{$\begin{array}{c}\text { Soaking Time (mins) } \\
60\end{array}$} & \multicolumn{4}{|c|}{ Wt. $\%$ Conc. of $\mathrm{NAClO}_{2}$} \\
\hline & & & \multirow{2}{*}{$\frac{1}{52}$} & \multirow{2}{*}{$\frac{2}{53}$} & \multirow{2}{*}{$\begin{array}{c}3 \\
55\end{array}$} & \multirow{2}{*}{$\begin{array}{c}4 \\
58\end{array}$} \\
\hline a & Alkali treated fiber at $2 \mathrm{wt} . \% \mathrm{NaOH}$ & & & & & \\
\hline & & 120 & 57 & 61 & 63 & 65 \\
\hline \multirow[t]{2}{*}{ b } & \multirow[t]{2}{*}{ Alkali treated fiber at 4 wt. $\% \mathrm{NaOH}$} & 60 & 58 & 66 & 74 & 78 \\
\hline & & 120 & 67 & 71 & 76 & 80 \\
\hline \multirow[t]{2}{*}{ c } & \multirow[t]{2}{*}{ Alkali treated fiber at 6 wt. $\% \mathrm{NaOH}$} & 60 & 55 & 56 & 64 & 66 \\
\hline & & 120 & 58 & 64 & 65 & 69 \\
\hline \multirow[t]{2}{*}{$d$} & \multirow[t]{2}{*}{ Alkali treated fiber at 8 wt. $\% \mathrm{NaOH}$} & 60 & 65 & 68 & 69 & 71 \\
\hline & & 120 & 73 & 77 & 78 & 86 \\
\hline \multicolumn{3}{|c|}{ Average cellulose content (\%) } & 60 & 65 & 68 & 72 \\
\hline
\end{tabular}

Table 2: Correlation of soaking time, percentage by weight concentration in extraction process of fiber cellulose content.

The first discusses the results on bleaching at varying $\mathrm{NaClO}_{2}$ concentration for both 60 and 120 minutes bleaching times for alkali treated fibers at $2 \mathrm{wt} . \% \mathrm{NaOH}$ for soaking times of 60 and 120 minutes. The second part discusses the bleaching results of alkali treated fibers at 4 wt. $\% \mathrm{NaOH}$ at both 60 and 120 minutes soaking time. While the third and fourth parts discusses the bleaching results of alkali treated fibers at 6 wt. $\%$ and 8 wt. $\%$ of $\mathrm{NaOH}$ with 60 and 120 minutes soaking times.

The highest cellulose percentage of $59 \%$ was measured for fiber, bleached at $4 \mathrm{wt} . \% \mathrm{NaClO}_{2}$, soaked for 120 minutes. This represents an increase of $41 \%$ in cellulose percentage composed to no bleaching of the fiber. However, increasing $\mathrm{NaClO}_{2}$ concentration and soaking time during bleaching have further increased the amount of cellulose percentage of the extracted fiber. Interesting the trend is proportional to the increment in $\mathrm{NaOH}$ concentration from the alkali treatment. It is also observed that soaking time have plenty of effect on the fiber cellulose content extracted. For example, at 2 wt. $\% \mathrm{NaOH}$ and $1 \mathrm{wt} . \%$ $\mathrm{NaClO}_{2}, 52$ wt.\% cellulose content was measured at 60 minutes soaking time whereas $57 \mathrm{wt} \%$ was measured for 120 minutes.

The measured values in part (b) shows the highest cellulose percentage of $65 \%$ was measured for fiber, bleached at 4 wt. $\%$ $\mathrm{NaClO}_{2}$, soaked for 120 minutes. This represents an increase of $47 \%$ in cellulose percentage composed to no bleaching of the fiber, an increment compared to that observed in Part a. The measured average enhancement in the cellulose content is $16 \%$ due to further bleaching of the alkali treated fiber i.e. $2 \mathrm{wt} . \%, 60$ minutes at $1 \mathrm{wt} . \% \mathrm{NaClO}_{2}$. When 2 wt.\% $\mathrm{NaClO}_{2}$ bleaching was involved, an average increment of $6 \%$ is measured when the soaking time is increased from 60 minutes to 120 minutes. Meanwhile for the samples (c), the highest cellulose percentage measured was $74 \%$ for fiber, bleached at 4 wt. $\% \mathrm{NaClO}_{2}$, soaked for 120 minutes. This represents an increase of $43 \%$ in cellulose percentage composed to no bleaching of the fiber, whereas the highest cellulose percentage of $86 \mathrm{wt} . \%$ was achieved at $4 \mathrm{wt} . \%$ with soaking time of 120 minutes. This represents an increment of 58\% compared to no bleaching of the $2 \mathrm{wt} . \%, 60 \mathrm{~min}$ alkali treatment fibers. For alkali treated fibers at $2 \mathrm{wt} . \%, 120$ minutes soaking time, the cellulose percentage has shown a more remarkable increase. Bleaching at 1 wt.\% for 60 minutes resulted in $21 \%$ increment in cellulose percentage (compared to $18 \%$ for alkali treated at $2 \mathrm{wt} . \%, 60$ minutes). As the soaking time increases to 120 minutes the cellulose percentage further increased by $12 \%$.

Based on the results on cellulose content determination of both alkali treated and combined alkali-bleach treated fibers, it was demonstrated that cellulose percentage of extracted fibers increases as concentration of the chemical reagent increases and also as the treatment or soaking time increases. However, the quality of extracted fiber does not only depend on the amount of cellulose but also on the

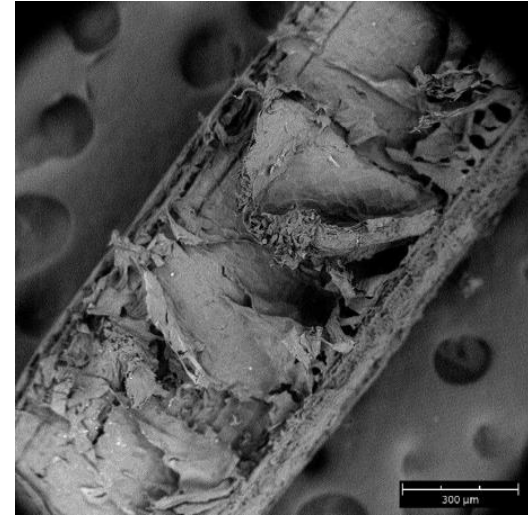

Figure 3: Fibril Microstructure of Untreated Screw-pine Fiber.

microstructure of the fibers. Ultimately, the highest quality of extracted fiber should also results in highest tensile strength of the fiber.

\section{Morphological analysis}

The morphological analyses were done to examine the microstructure of the screw-pine strips. The microstructures of the screw-pine strips were observed before and after treatment which included the untreated, after alkali treatment and after the combined alkali-bleach treatments.

Untreated screw-pine fiber: The image depicting the microfibril of the single screw-pine fiber before treatment is mentioned in Figures 3 and 4 . The microfibril is wrapped by hemicellulose and lignin on the outer surface. As a consequence, it created an impurities layer on the microfibril. Those impurities will cause poor adhesion between epoxy matrix and the fiber. Thus, the strength of the composite could suffer. Hemicellulose and lignin bond is in form of amorphous, thereby depicting a weak structure. Therefore, the removal of the hemicellulose and lignin in an extraction process is required for improved bonding between composite matrix and fiber.

Alkali treatment fiber: Longitudinal cross-section of the screwpine strips after alkali treatment at various $\mathrm{NaOH}$ concentrations and soaking time is shown in Figures 5-7 by scanning electron micrographs (SEM) imaging. The SEM imaging clearly shows presence of hemicellulose and lignin on the microfibrils after being treated with 2 wt.\% $\mathrm{NaOH}$ at 60 minutes in Figure 5a. The structures were still held closed-up together while the void sizes is small, the reason is as a result of the process parameters inability to completely remove the cementing substances (Figure 5).

Furthermore, Figure 5b clearly shows the fibers intact and well 


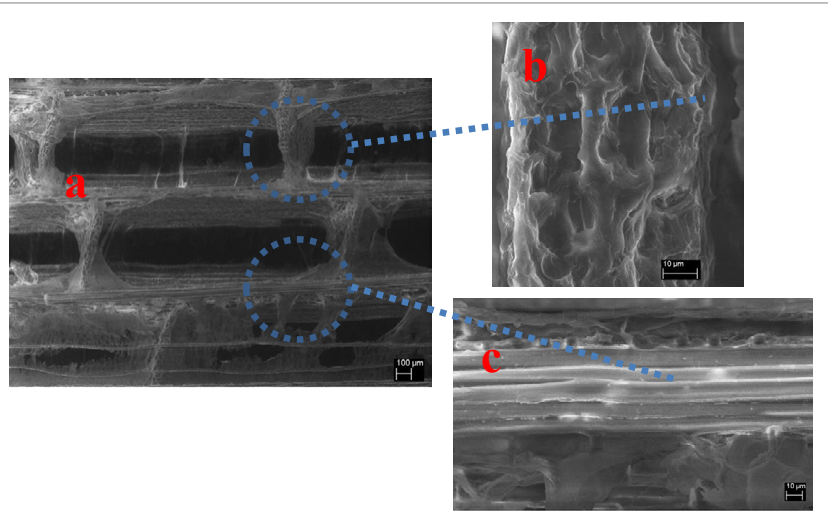

Figure 4: Microstructure of Untreated Screw-pine leaf strip: (a) Lines of Microfibrils from Screw-pine Strip (50x Magnification), (b) Hemicellulose and Lignin Structure of the Screw-pine Mat, (100x Magnification), (c) Microfibril Structure of Screw-pine Strip (100x Magnification).
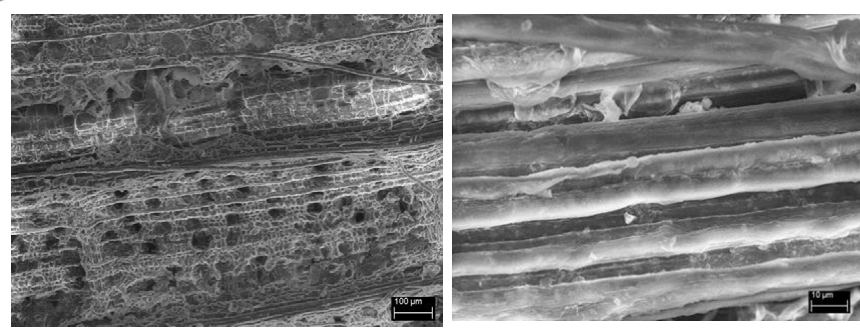

Figure 5: Micrographs of Alkali Treated screw-pine Leaf Strips a) Microstructure of Alkali Treated Fiber at 2 wt. $\% \mathrm{NaOH}$ for 60 minutes (50x Magnification) b) Microfibril Structure of Alkali Treated fiber at $2 \mathrm{wt} . \% \mathrm{NaOH}$ for 60 minutes (500x Magnification).

bonded. Although different behaviour is observed when the soaking time was doubled as displayed in Figure 6a. The SEM image in Figure 6a showed the much bigger void sizes indicating breakdown of the bond structure compared to Figure 5a. In addition, smaller particles and dribs are noted in Figure 5b, this implies that there are fiber content remaining in the strip, incomplete extraction process. However, increasing the chemical concentration and soaking can improve the extraction process. As an example, measured value from 6 and 8 wt.\% clearly showed weaker cementite bonding in the fibril and the void space were very small. The breaking down of fiber or microfibrils was due to high alkali concentration used, the fiber structure became distorted due to the removal of cementing material such as hemicellulose. Surely distortion will have effect on the characteristics of the fibril (Figures 6 and 7).

The Figure $7 \mathrm{a}$ and $7 \mathrm{~b}$ captured the SEM micrograph of the continuous cellulose fibril (a single fiber strand), after alkali treatment at varying extraction parameters. Several microfibrils are contained in the cellulose fibril and reduction in diameter of the continuous fibrils due to alkali treatment is observed. Similar observation was reported on alkali treated agave and borassus fruit fiber [22,23]. Diameter of fibril was reduced as alkali concentration and soaking time increased. This was due to removal of impurities from the surface of the fibril.

Combined alkali and bleaching treatment fiber: The alkali treated screw-pine strips at 2, 4, 6 and 8 wt.\% concentration at both 60 and 120 minutes soaking times were further treated with bleaching. The influence of bleaching on the alkali treated strips was examined by visual inspection and microstructural analysis. The longitudinal cross-

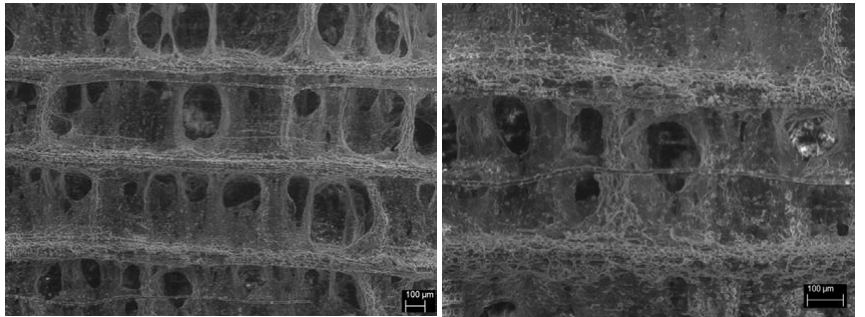

Figure 6: Micrographs of Alkali Treated screw-pine Leaf Strips a) Microstructure of Alkali Treated Fiber at $4 \mathrm{wt} . \% \mathrm{NaOH}$ for 120 minutes (50 Magnification) b) Microfibril Structure of Alkali Treated Fiber at $4 \mathrm{wt} . \% \mathrm{NaOH}$ for 120 minutes (100x Magnification)
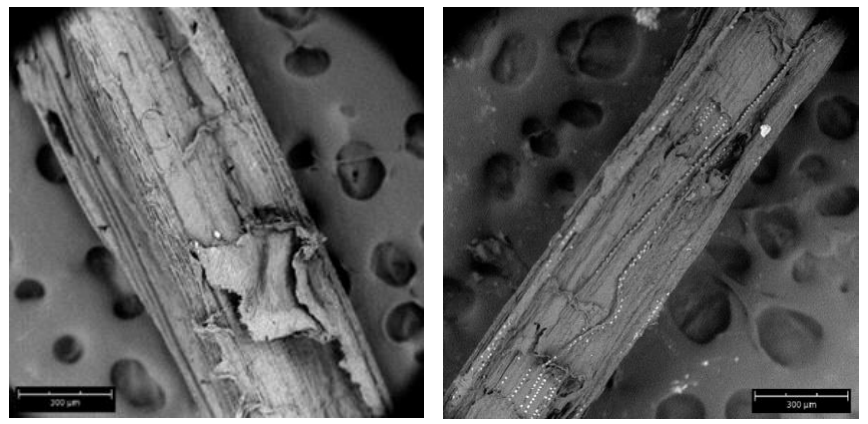

Figure 7: Scanning Electron Micrographs of the screw-pine Fibril after Alkal Treatment at a) 2 wt. $\% \mathrm{NaOH}$ for 60 minutes b) 2 wt. $\% \mathrm{NaOH}$ for 120 minutes. All Micrographs are at 500x Magnification.
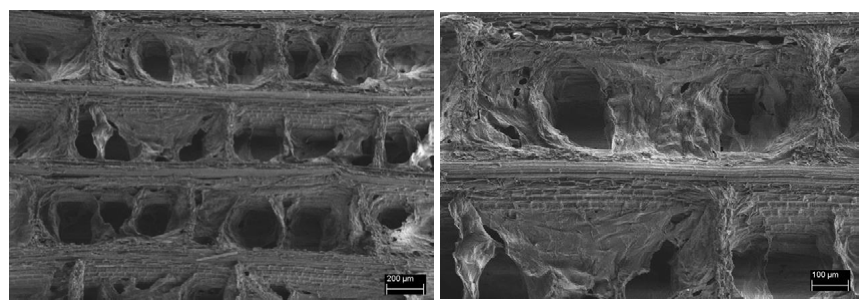

Figure 8: Scanning Electron Micrographs of screw-pine Leaves after Bleaching at $1 \mathrm{wt} . \% \mathrm{NaClO}_{2}$ for 60 minutes following Alkali Treatment at $2 \mathrm{wt} \% \mathrm{NaOH}$ for 60 minutes a) Leaf Microstructure (50x Magnification) b) Microfibril Microstructure (100x Magnification).

section of the alkali-bleach screw-pine leaves is shown in Figures 8-10 by SEM micrograph. All the bleached screw-pine leaves were alkali treated with mentioned extraction process parameters. Figure 8 shows microstructure of the bleached leaf at $1 \mathrm{wt} . \% \mathrm{NaClO}_{2}$ for $60 \mathrm{~min}$ after undergone alkali treated at $2 \mathrm{wt} . \% \mathrm{NaOH}$ at 60 minutes soaking time (Figure 8).

The structural arrangement depicted in Figure $8 \mathrm{a}$ is notably still packed and covered with hemicellulose and lignin, although the bonding is weak and distorted. The cell structure is not regular in formation. However, single fibers containing microfibrils are still closely packed, extending the soaking time can reasonable remove all the left weak bonding and void space.

When the soaking time is increased to 120 minutes during the alkali treatment and increasing the chlorite concentration from 1 to $2 \mathrm{wt} . \%$ resulted in considerable changes in the microstructure of the leaf as shown in Figure 9. More hemicellulose and lignin were bleached away and in fact defibrillation start to set-in, although the microfibrils were still intact (Figure 9). 

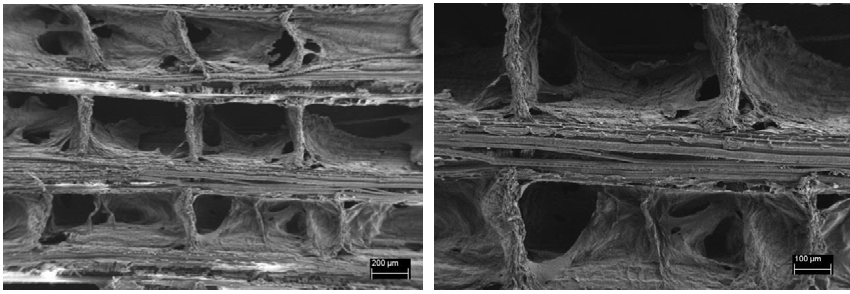

Figure 9: Scanning Electron Micrographs of screw-pine Leaves after Bleaching at $2 \mathrm{wt} \% \mathrm{NaClO}_{2}$ for 60 minutes following Alkali Treatment at $4 \mathrm{wt} . \% \mathrm{NaOH}$ for 120 minutes a) Leaf Microstructure (50x Magnification) b) Microfibril Microstructure (100x Magnification)
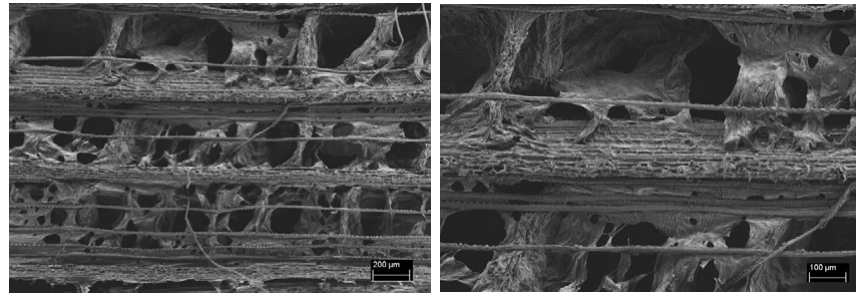

Figure 10: Scanning Electron Micrographs of Mengkuang Leaves after Bleaching at $3 \mathrm{wt} \% \mathrm{NaClO}_{2}$ for 120 minutes following Alkali Treatment at 6 wt.\% NaOH for 120 minutes a) Leaf Microstructure (200x Magnification) b) Microfibril Microstructure (500x Magnification).

Bleaching does not only remove the lignin but also the Hollocellulose of the natural fiber [24]. This is depicted in Figure 10a and 10b. Further defibrillation is also observed as the percentage concentration of the $\mathrm{NaClO}_{2}$ and soaking time is increased, particularly from 4 to $8 \mathrm{wt} . \%$. The bundle of fibers started to separate into elementary fibers as illustrated in Figure 10a and 10b.

The bleaching treatment causes rapidly oxidized lignin due to the chlorine content. This act causes degradation lignin content. Figure 11 shows the SEM micrograph screw-pine after 4 wt.\% $\mathrm{NaClO}_{2}$ for 120minutes after alkali treatment. Complete structural disorder was observed in the microstructure of the bleached leaf at $4 \mathrm{wt} . \% \mathrm{NaClO}_{2}$ for 60 and 120 minutes for alkali treated at 8 and 6 wt.\% NaOH for 120 mins respectively. The rectangular structure became wider; hemicellulose and lignin were completely removed. The fiber bundles were no more intact, separated from its bundle. Though, the cellulose fibers started to show sign of degradation.

Figure 12 demonstrated the effects of combined alkali-bleaching treatment on fibrils microstructure of the screw-pine leaves. Bleaching the alkali treated leaf ( $2 \mathrm{wt} . \% \mathrm{NaOH}, 60$ mins) at $1 \mathrm{wt} . \% \mathrm{NaClO}_{2}$ for 60 minutes was not very effective in removing the hemicellulose and lignin content. Increasing the bleaching time to 120 minutes alone, resulted in smoother surface of the fibril.

The extended bleaching time allowed more effective extraction of the lignin. The combined treatments have caused the elementary fibers to be exposed due to complete removal of hemicellulose and lignin. Although some degradation in the cellulose was observed, meaning the combined alkali-bleaching did not only remove completely the cementite bond but gave some negative effect on the fiber content.

\section{Cellulose yield content}

The cellulose yield percentage is plotted against soaking time and chemical concentration in Figures 13-16. Among all the various
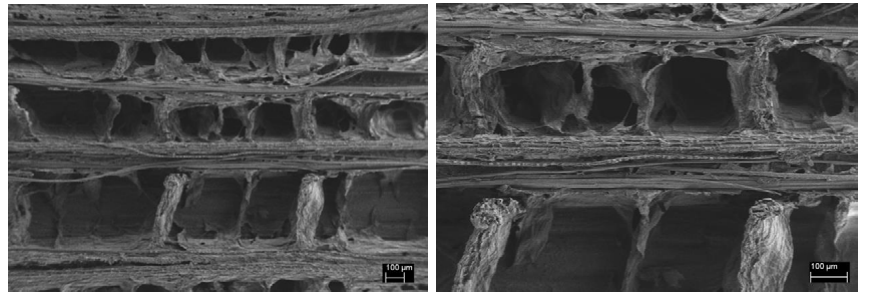

Figure 11: Scanning Electron Micrographs of screw-pine Leaves after Bleaching at 4 wt. $\% \mathrm{NaClO}_{2}$ for 120 minutes following Alkali Treatment at 8 wt.\% $\mathrm{NaOH}$ for 60 minutes a) Leaf Microstructure (50x Magnification) b) Microfibril Microstructure (100x Magnification).
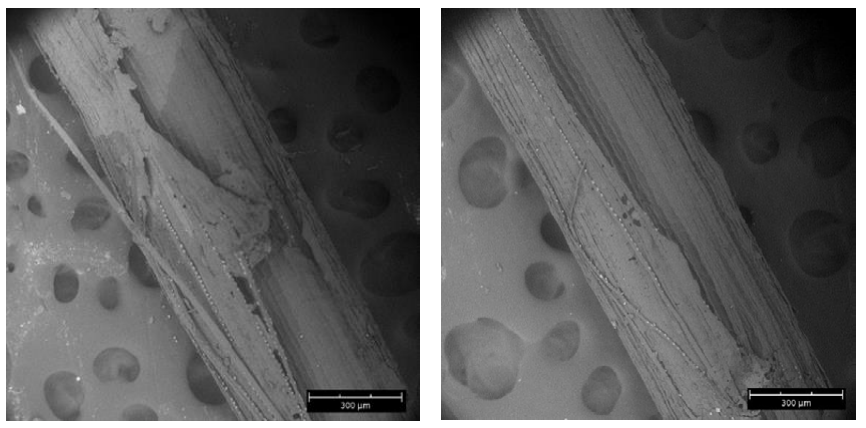

Figure 12: Microstructure of Fribil after Combined Alkali-Bleach Treatment a) Alkali Treatment at $2 \mathrm{wt}$ \% $\mathrm{NaOH}$ for 60 minutes followed by bleach $1 \mathrm{wt} . \%$ $\mathrm{NaClO}_{2}$ for 60 minutes b) Alkali Treatment at $2 \mathrm{wt} \% \mathrm{NaOH}$ for 60 minutes followed by bleaching $1 \mathrm{wt} \% \mathrm{NaClO}_{2}$ for 120 minutes (500x Magnification).

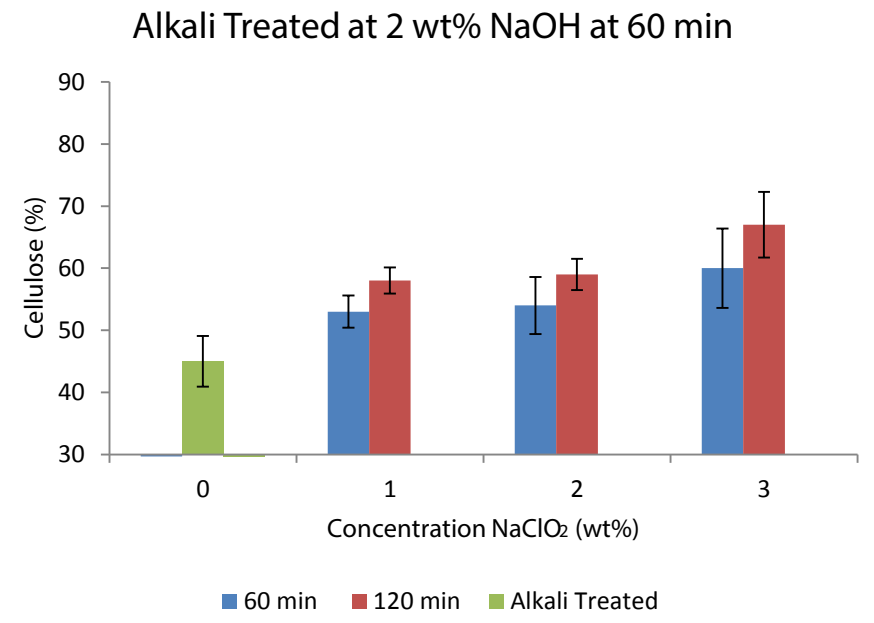

Figure 13: Plot of cellulose yield content against process-parameter of screwpine Leaves after Bleaching at 1, 2, $3 \mathrm{wt} . \% \mathrm{NaClO}_{2}$ for 60 minutes following Alkali Treatment at $2 \mathrm{wt} \% \mathrm{NaOH}$ for 60 minutes.

process-parameter evaluated, only the yield content of the fiber cellulose for combined alkali-bleached treatment is considered and presented. The 2 wt.\% $\mathrm{NaOH}$ at 60 and 120 minutes is plotted in Figures 13 and 14 respectively.

The yield content of the cellulose increases with increase in the chemical concentration and soaking time. However, optimal measured value for yield increment is at $3 \mathrm{wt} . \% \mathrm{NaClO}_{2}$ whereas the 1 and $2 \mathrm{wt} . \%$ of $\mathrm{NaClO}_{2}$ should no enhancement in the cellulose. The percentage increment in cellulose content is estimated at $8 \%$ when the $\mathrm{NaClO}_{2}$ is varied in ascending order for both soaking time, but it is noted that the 
Citation: Owolabi AL, Megat-Yusoff PSM (2018) Characterization and Analysis of Extraction Process-parameter of Pandanus tectorius (Screw-pine) Natural Fiber for Polymer Composites. J Material Sci Eng 7: 425. doi: 10.4172/2169-0022.1000425

soaking time have limited effect when $2 \mathrm{wt} . \%$ of $\mathrm{NaClO}_{2}$ was used in the combined treated (Figures 15 and 16).

The increment in chemical concentration from 2 to $4 \mathrm{wt} . \%$ of $\mathrm{NaOH}$ alkali treated and subsequently increasing the bleaching chemical concentration should slim difference in terms of yield content. A mere $2.5 \%$ increment was measured. The small difference can be traced to the reduction in the void space and further breaking down of the bond structure. In all, the different treatment has increased tremendously the

\section{Alkali Treated at $2 \mathrm{wt} \% \mathrm{NaOH}$ at $120 \mathrm{~min}$}

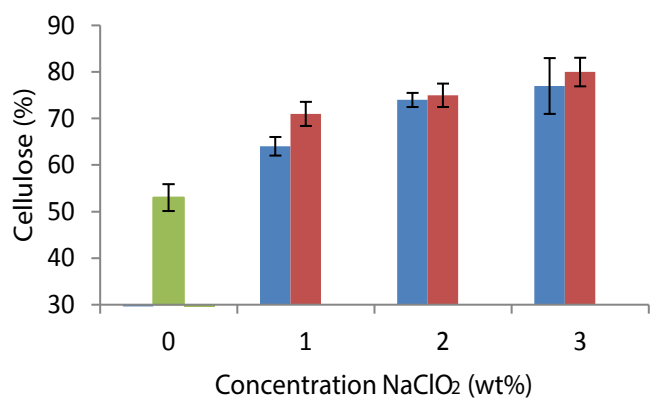

$\square 60 \mathrm{~min} \quad \square 120 \mathrm{~min} \square$ Alkali Treated

Figure 14: Plot of cellulose yield content against process-parameter of screwpine Leaves after Bleaching at 1, 2, 3 wt. $\% \mathrm{NaClO}_{2}$ for 120 minutes following Alkali Treatment at $2 \mathrm{wt} . \% \mathrm{NaOH}$ for 120 minutes.

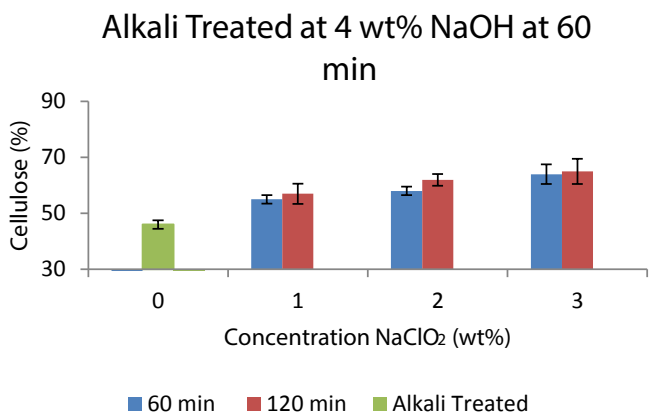

Figure 15: Plot of cellulose yield content against process-parameter of screwpine Leaves after Bleaching at 1, 2, 3 wt. $\% \mathrm{NaClO}_{2}$ for 60 minutes following Alkali Treatment at $4 \mathrm{wt} \% \mathrm{NaOH}$ for 60 minutes.

\section{Alkali Treated at 4 wt\% $\mathrm{NaOH}$ at 120 $\min$}

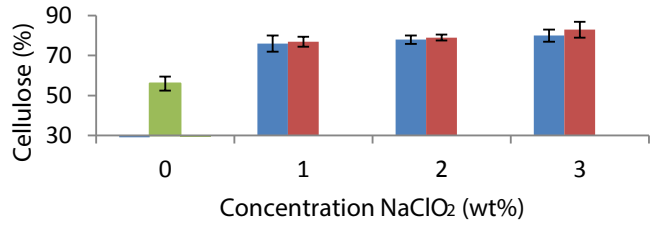

-60 min $\quad 120 \mathrm{~min} \quad$ Alkali Treated

Figure 16: Plot of cellulose yield content against process-parameter of screwpine Leaves after Bleaching at 1, 2, $3 \mathrm{wt} . \% \mathrm{NaClO}_{2}$ for 120 minutes following Alkali Treatment at $4 \mathrm{wt} . \% \mathrm{NaOH}$ for 120 minutes. yield content compared to the un-treated yield measured. In addition, the bleaching further enhanced the cellulose content by $25 \%$. The effect of the processing parameters varied are obvious on the cellulose yield content however, an optimal process-parameter is need to get the best cellulose fiber devoid of degradation.

\section{Conclusion}

Conclusively, the morphological analyses carried out on each of the treated fiber have considerable effect on the extraction, chemical concentration and soaking time. Higher cellulose percentage can be obtained by increasing the chemical concentration and soaking time, however, fiber roughening and separation of the elementary fiber are the observed set-back. However, if the impurities can be separated very well, this set-back may as well be overcome. Increasing the $\mathrm{NaClO}_{2}$ concentration and soaking caused defibrillation to occur. Nonetheless, it is an indicator of complete removal of the hemicellulose and lignin. Void space and weaken of the bond is reduced or eliminated but porosity also increased.

In brief, higher cellulose fiber content can be obtained by increasing the process parameters, although caused some damage to the cellulose fiber structure. In view of the set-back, optimum extraction process parameters should be considered to obtain smooth fiber surface and intact microfibrils structure. The present study observed optimal parameter in range of 6 and 8 wt. $\%$ of $\mathrm{NaOH}$ alkali treated and 2 and 3 wt.\% of $\mathrm{NaClO}_{2}$ after passing through 4 and 6 wt.\% $\mathrm{NaOH}$ respectively. Further investigation on the continuous cellulose fibers extraction using the combined alkali-bleach treatment can be investigated for possible usage in polymer composite for engineering applications.

\section{Acknowledgement}

The research reported in this paper was supported by fundamental research grant (FRG-UTP) university technology PETRONAS. This support was gratefully acknowledged.

\section{References}

1. Shaikh H, Andaç M, Memon N, Bhanger MI, Nizamani SM, et al. (2015) Synthesis and characterization of molecularly imprinted polymer embedded composite cryogel discs: application for the selective extraction of cypermethrins from aqueous samples prior to GC-MS analysis. RSC Advances 5: 26604-26615.

2. Chaudhary V, Gohil PP, Shaikh AA (2015) Development of Potential Composites through Natural Fiber Reinforcement.

3. Tsunoda M, Kido T, Mogi S, Sugiura Y, Miyajima E, et al. (2014) Skin irritation to glass wool or continuous glass filaments as observed by a patch test among human Japanese volunteers. Industrial health 52: 439-444.

4. Verma D, Gope PC, Shandilya A, Gupta A, Maheshwari MK (2013) Coir fibre reinforcement and application in polymer composites: A. Journalof Material \& Environment Science 4: 263-276

5. Neto ARS, Araujo MA, Souza FV, Mattoso LH, Marconcini JM (2013) Characterization and comparative evaluation of thermal, structural, chemical, mechanical and morphological properties of six pineapple leaf fiber varieties for use in composites. Industrial Crops and Products 43: 529-537.

6. Nagarajan V, Misra M, Mohanty AK (2013) New engineered biocomposites from poly (3-hydroxybutyrate-co-3-hydroxyvalerate)(PHBV)/poly (butylene adipate-co-terephthalate)(PBAT) blends and switchgrass: Fabrication and performance evaluation. Industrial crops and products 42: 461-468.

7. Thakur VK, Thakur MK (2014) Processing and characterization of natural cellulose fibers/thermoset polymer composites. Carbohydrate polymers 109 102-117.

8. Fiore V, Scalici T, Valenza A (2014) Characterization of a new natural fibe from Arundo donax L. as potential reinforcement of polymer composites. Carbohydrate polymers 106: 77-83.

9. Al-Oqla FM, Sapuan SM (2014) Natural fiber reinforced polymer composites in 
Citation: Owolabi AL, Megat-Yusoff PSM (2018) Characterization and Analysis of Extraction Process-parameter of Pandanus tectorius (Screw-pine) Natural Fiber for Polymer Composites. J Material Sci Eng 7: 425. doi: 10.4172/2169-0022.1000425

Page 8 of 8

industrial applications: feasibility of date palm fibers for sustainable automotive industry. Journal of Cleaner Production 66: 347-354.

10. Reddy KO, Ashok B, Reddy KRN, Feng YE, Zhang J, et al. (2014) Extraction and characterization of novel lignocellulosic fibers from Thespesia lampas plant. International Journal of Polymer Analysis and Characterization 19: 48-61.

11. Saravanakumar SS, Kumaravel A, Nagarajan T, Sudhakar $P$, Baskaran $R$ (2013) Characterization of a novel natural cellulosic fiber from Prosopis juliflora bark. Carbohydrate polymers 92: 1928-1933.

12. Kim H, Okubo K, Fujii T, Takemura K (2013) Influence of fiber extraction and surface modification on mechanical properties of green composites with bamboo fiber. Journal of Adhesion Science and Technology 27: 1348-1358.

13. Kommula V, Reddy KO, Shukla M, Marwala T, Reddy ES, et al. (2016) Extraction, modification, and characterization of natural ligno-cellulosic fiber strands from napier grass. International Journal of Polymer Analysis and Characterization 21: 18-28.

14. Gunnarsson S (2003) Optimisation of N release V: 381

15. Beck S, Méthot M, Bouchard J (2015) General procedure for determining cellulose nanocrystal sulfate half-ester content by conductometric titration. Cellulose 22: 101-116

16. Neto VDOS, Cláudio F, Paulo de Tarso C, Araujo-Silva MA, do Nascimento RF (2015) Modifications of lignocellulose fibers and Its application In adsorption of Heavy metals from aqueous solution. Surface Modification of Biopolymers pp: 113 .

17. Ramavandi B, Akbarzadeh S (2015) Removal of metronidazole antibiotic from contaminated water using a coagulant extracted from Plantago ovate. Desalination and Water Treatment 55: 2221-2228.

18. Jadhav AJ, Holkar CR, Goswami AD, Pandit AB, Pinjari DV (2016) Acoustic Cavitation as a Novel Approach for Extraction of Oil from Waste Date Seeds. ACS Sustainable Chemistry \& Engineering 4: 4256-4263.

19. Ezeh O, Gordon MH, Niranjan K (2016) Enhancing the recovery of tiger nut (Cyperus esculentus) oil by mechanical pressing: Moisture content, particle size, high pressure and enzymatic pre-treatment effects. Food chemistry 194: 354-361.

20. Rong MZ, Zhang MQ, Liu Y, Yang GC, Zeng HM (2001) The effect of fiber treatment on the mechanical properties of unidirectional sisal-reinforced epoxy composites. Composites Science and technology 61: 1437-1447.

21. Gassan J (1997) Natural fibre-reinforced plastics-correlation between structure and properties of the fibres and the resultant composites. Unpublished doctoral dissertation, University of Kassel, Kassel, Germany.

22. Mylsamy K, Rajendran I (2011) Influence of alkali treatment and fibre length on mechanical properties of short Agave fibre reinforced epoxy composites. Materials \& Design 32: 4629-4640.

23. Boopathi L, Sampath P, Mylsamy K (2012) Investigation of physical, chemical and mechanical properties of raw and alkali treated Borassus fruit fiber. Composites Part B: Engineering 43: 3044-3052.

24. Ching YC, Ng TS (2014) Effect of preparation conditions on cellulose from oil palm empty fruit bunch fiber. BioResources 9: 6373-6385. 